\title{
Analysis and Evaluation of Traffic Congestion Control Methods in Touristic Metropolis Using Analytical Hierarchy Process (AHP)
}

\author{
Masoud Kadkhodaei ${ }^{\mathrm{b}}$, Rouzbeh Shad ${ }^{\mathrm{b} *}$ \\ ${ }^{a}$ PhD. Student, Faculty of Engineering, Ferdowsi University of Mashhad, Mashhad, Iran. \\ ${ }^{b}$ Assistant Professor, Faculty of Engineering, Ferdowsi University of Mashhad, Mashhad, Iran.
}

Received 05 January 2018; Accepted 16 March 2018

\begin{abstract}
One of the most important issues of urban transport management in metropolitan cities is the control of traffic congestion in the central parts of the city or other densely populated areas. Typical ways to control traffic congestion in metropolitan areas are to create a prohibited traffic area, alternate traffic plan (even and odd), and congestion pricing. In this paper, these traffic congestion control methods have been compared and evaluated. The methodology of this research is analytical hierarchy analysis (AHP). Based on the results, the most effective measures for assessing traffic congestion control methods in metropolitan cities were improving traffic conditions, social welfare, reducing environmental pollution and improving the safety of intra-urban travel. The best Traffic congestion control options were also priced for traffic congestion, roaming traffic (odd and odd), and the creation of traffic barriers. The results of analyzes and paired comparisons in analytic hierarchy analysis were also obtained using "Expert choice" software.
\end{abstract}

Keywords: Prohibited Traffic Area; Alternate Traffic Plan; Traffic Congestion Pricing; Analytical Hierarchy Analysis.

\section{Introduction}

In metropolitan cities, there are typically three general policies to solve the high traffic congestion problem in the city's central districts: 1- Prohibited traffic area; 2- Alternate traffic plan; 3- Congestion pricing. In the policy of creating a prohibited traffic area, within a specific time period of the day, the entry of all vehicles except public transportation vehicles is prohibited. Given the fact that most state and economic centers in metropolitan cities are deployed in urban centers, problems such as increased traffic in central areas, lack of suitable parking spaces in these areas, increased vehicle fuel consumption due to long and Air pollution is probable and predictable. Therefore, regulating the traffic flow of cars in the central metropolitan area and preventing any traffic jams is considered as one of the most important issues of transport management in metropolitan areas. One of the reasons for carrying this issue, which is currently being used in many major cities of the world, is the introduction of traffic congestion into city centers or highways. In these designs, public transport vehicles and ambulances are generally allowed to enter the area without any restrictions. Also, vehicles that are licensed for traffic can be entered into the range with special labels.

In the policy of Alternate traffic plan, every day, only a portion of personal vehicles are allowed to enter the traffic area. Usually, this scheme is implemented that allows for entering into the area of the traffic plan into cars with a pair of plains on the special days of the week and on the other days to cars with an individual plaque (even and odd). In this way, the last digit of the license plate number is used to quit their traffic. In the implementation of this method, a range usually from the central and commercial areas of the city and physically crowded is considered as the scope of the design and the entry of vehicles into the area is fixed on certain days of the week. The assigned pattern for vehicle

* Corresponding author: rouzbeh_shad@yahoo.com

doi http://dx.doi.org/10.28991/cej-0309119

$>$ This is an open access article under the CC-BY license (https://creativecommons.org/licenses/by/4.0/).

(C) Authors retain all copyrights. 
traffic quota is divided into two fixed and variable traffic schedules along the run-time. In the static pattern, the traffic quota for cars on weekdays is based on the last digit of the license plate, an executive program for driving vehicles on all days of the week is presented within the scope of the plan. Drivers of vehicles according to this pattern are allowed to enter the area on some days of the week. In this way, vehicles will not have any predictions as to how the traffic will be quoted. For example, it may be presented in a pattern on a particular day only even numbers, only odd numbers or a combination of both, to be submitted. Therefore, supportive households cannot buy vehicles with specified numbers on specific days. However, in even and odd plan, families can pick up their need for the whole day by purchasing a vehicle with an even number and a vehicle with an odd number.

In pricing policies, it is also a price to enter a traffic plan range where private car drivers are required to pay for that route to enter the traffic area or cross certain streets. In general, there are two approaches to increasing supply and demand management to control traffic congestion. Increasing supply means developing and increasing the capacity of public transport and transit routes but experience has shown that rising supply after a while has increased travel demand, which will increase the congestion again. On the other hand, supply increases the need for economic resources, which governments and municipal authorities often fail to provide without paying taxes. One of the most important approaches used to manage demand is the use of road pricing method [1].

The initial idea of pricing a route by Pigou in 1920 was used in an example to calculate the optimal toll rates on a crowded road. The basic pricing principles are very simple and in fact are similar to the pricing principles of the commodity market. Complications should be lower in peak hours and in non-regular hours in order to control travel demand [2]. In 1979, Smith states the pricing of the network in theory, based on a fundamental and economic principle of cost-based social margin squeeze, in which any user of the system would use crowded and high-traffic arcs in order to maximize the surplus of the benefits of the entire community, it must be cost-effective in addition to the time spent traveling on the bow. These costs and benefits are equal to the difference between the overall marginal cost and the marginal cost of each user [3].

Each of these policies has its own advantages and disadvantages, and given the traffic situation of any metropolis, each of these policies may be superior to others. Therefore, in order to choose the best traffic control policy in metropolitan cities, and especially the large touristic cities, it is necessary to compare these three categories of policy with each other and analyze and evaluate them.

\section{Literature Review}

In a study by Ahmadi Azari et al. In 2013 on assessing the demand for various travel destinations in different scenarios for traffic congestion pricing, it has been concluded that the sensitivity of road users to the cost of traffic congestion and parking on business trips and non-working with each other is different. In this research, various pricing scenarios for passengers were presented and their responses were examined using a polynomial Logit model. Based on this study, since most travels in the central business district of Mashhad are business trips, parking pricing policies and traffic congestion pricing are effective in changing demand for business trips in central business districts, and the impact of non-operating trips there are more policies [4].

In a study by Zhou et al. In 2015, they have proposed a traffic congestion pricing model for elastic demand networks and capacity constraints that not only minimizes system costs but also limits capacity [5]. In a study by Lara et al. in 2013, the role of traffic congestion pricing in urban long-term planning is explored. Paris has also been selected as a case study in this research. In this study, two traffic pricing plans are based on the distance traveled in the range and traffic congestion pricing based on the cost of entering the range. The two designs are compared in two ways without increasing the operating costs of the vehicle and the first better mode of operation, which minimizes overall network costs. Based on the results of this study, the optimal pricing of traffic congestion in the absence of increased operating costs of the vehicle reduces the range of traffic planning penetration and average travel distance by $34 \%$ and $15 \%$ respectively [6].

Wang et al. (2015) have conducted research on daily pricing of traffic congestion and network resilience. One of the most important indicators of the flexibility of a traffic network is its speed of returning to the initial state after an interruption of the network. In this research, a daily pricing method for traffic congestion is proposed to increase the speed of the traffic network reversibility to the initial state after events such as floods, earthquakes, and so on. Numerical studies carried out in this study also show the improvement of the speed of reversibility of traffic jams after incidents and traffic disruptions as a result of daily traffic pricing schemes [7].

Daganzo and Lehe have conducted a survey on traffic pricing in districts of the city in 2015 . This study shows the heterogeneity and inconsistency of travel distance with traffic congestion pricing and suggests pricing traffic congestion based on distance traveled to make shorter trips to the central city areas, priority should be given to them. According to the results of this study, traffic congestion pricing according to the distance traveled compared to other traditional pricing schemes of traffic congestion has a greater effect on reducing traffic congestion [8]. 
In 2015, Amirgholy et al. conducted a study on multifunctional pricing of traffic congestion to control long-term traffic congestion in large urban areas. In this research, traffic congestion pricing has been considered as an effective factor in transport demand management, and using a two-level optimal model, pricing has been made for a central business district of the city. According to the results of this study, various groups of travelers in shopping centers like buyers, retailers, and simple business staff ... each have a different sensitivity to traffic congestion pricing [9].

In 2011, Palma and Lindsey investigated methods and techniques for pricing traffic congestion. Street traffic pricing can be implemented on a wide scale from separate lines to single connections to road networks. Traffic congestion pricing can vary according to different hours of the day, type of route, vehicle specifications, and traffic conditions. Compliance systems are often mechanized and using electronic technology. Traffic and road pricing depends on the technology used [10].

Wang et al. (2013) have done research on the impact of traffic congestion on traffic safety. The hypothesis of this study was to reduce the number of severe crashes and injuries by increasing traffic congestion due to the low average speed of cars in traffic congestion. The results of this study show that increased traffic congestion is more effective on severe crashes and leads to life-threatening injuries and less impact on minor crashes [11].

Cao et al., in 2017, has conducted a study on the development of an integrated framework for vehicle navigation and traffic lights control to reduce traffic congestion. In this study, the ABEONA algorithm for routing and controlling traffic lights has been suggested that, compared to other monitoring methods, the installation and maintenance costs are less. Also, this algorithm has fewer overhead than other methods, it is possible to predict potential traffic congestion and re-routing based on it [12].

Wang et al., in 2017, conducted a study on the correlation of traffic congestion between different parts of the road. Previous studies have often focused on the prediction of traffic congestion and the analysis of traffic flows, but this study examines the potential relevance of traffic congestion in different parts of the road. According to the results of this research, the correlation of the traffic flow congestion with a certain orientation is transferable [13].

Wang et al., in 2016, conducted a study on the provision of a multipurpose system for optimal routing and noninterception in unpredictable traffic congestion. Abrupt traffic congestion caused by accidents such as traffic accidents during peak hours in urban areas can increase drivers' travel time and reduce the reliability of trips seriously. Based on the results of this study, the proposed routing system in this study compared with other models can produce a route with lower average travel time and more reliability [14].

Sun et al., in 2014 have been investigating the spatial distribution of traffic congestion and traffic jams in different topologies. In recent years, traffic congestion has become a common social problem. The production and expansion of traffic congestion is also closely related to network topology, traffic flow, and so on. This study examines the characteristics of time distribution and traffic space and bottlenecks in different network topologies based on the traffic flow distribution method. According to the results of this research, a random network is a desirable traffic structure in which traffic congestion is less. Regular network is also the worst topology that is prone to traffic congestion [15].

In 2017, Ding et al. Have done research on the role of traffic routing and traffic control in addressing the traffic congestion problem in large traffic networks. This study proposes simultaneous routing with traffic control to improve the performance of large traffic networks. Based on the results of this study, the proposed method reduces the total delay in the network [16].

\section{Study Area}

Mashhad is the second largest metropolis in Iran, with 3.5 million inhabitants. Every year, more than 25 million passengers travel to the city. The number of passengers in some seasons and special times and holidays has increased greatly and causes many traffic problems for citizens and travelers. On the other hand, the number of citizens traveling in the central part of the city is more than the capacity of streets and streets in the city's central area. Therefore, in recent years, the alternate traffic plan has been implemented in the central part of Mashhad city. The objectives of this project were to reduce traffic, reduce fuel consumption and reduce air pollution in the central area of Mashhad.

In this plan, cars with even number in the last digit of their plaques can travel on Saturdays, Mondays and Wednesdays and the cars with the last digit of their plaques are odd can travel on Sundays, Tuesdays and Thursdays. On Fridays and holydays, all vehicles are also within the scope of the free plan. The period of implementation of this project is also from 8 to 20 o'clock, which increases in certain times. The area boundaries of this traffic plan is shown in Figure 1. 


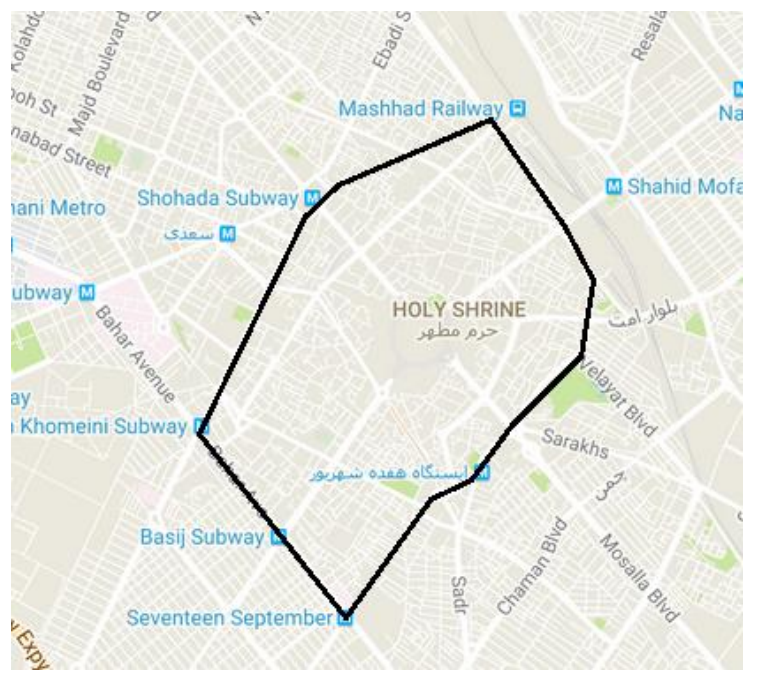

Figure 1. Area of traffic planning in Mashhad

\section{Methodology}

In this research, Analytical Hierarchy Process (AHP) method has been used to evaluate the traffic congestion control methods in touristic cities. First, the technical and economic and social criteria that are effective in assessing the traffic control constraints in the metropolitan areas are selected and then, according to the experts of transportation, the weight of each of the criteria and sub-criteria is determined. Then, the rating of each of the traffic congestion control options in each of the criteria and sub-criteria is presenting based on experts' opinions and for the Mashhad metropolis. Using the weight assigned to the criteria and sub-criteria, the final score of each option is specified and based on it, metropolitan traffic control options for touristic cities are ranked in order of priority. Flowchart of this methodology is shown in Figure 2.

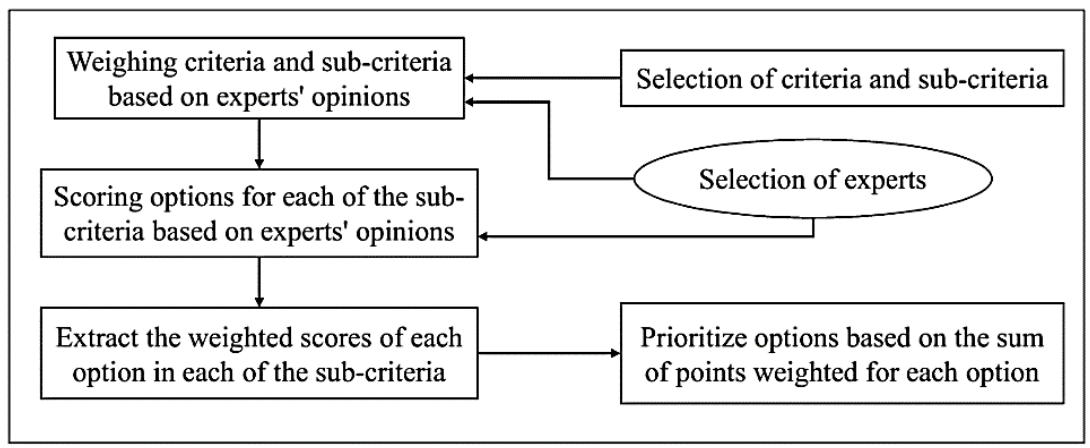

Figure 2. Flowchart of the methodology used for analysis and evaluation

In this paper, the opinions of the 20 experts in the field of transportation and traffic that have passed the master's degree in transportation have been used. According to past studies and projected targets for traffic congestion control plans in metropolitan cities, four general categories for assessing traffic congestion control methods in metropolitan cities have been selected in this study. These criteria and sub-criteria are shown in Table 1.

Analyzing Hierarchical Analytic Method (AHP) is a suitable method for evaluating these methods, because of any Dependence between selected criteria of assessment and their sub criteria and also between the options for control of traffic congestion of touristic cities are not considered.

Table 1. Metrics for assessing metropolitan traffic congestion control methods

\begin{tabular}{cc}
\hline Criteria & Sub criteria \\
\hline Traffic & $\begin{array}{r}\text { Increasing the using of public transport } \\
\text { Reducing the traffic of single-seat vehicles } \\
\text { Reducing the driving violations }\end{array}$ \\
\hline \multirow{2}{*}{ Social Welfare } & Decrease travel time \\
Environmental & Reduce travel costs \\
\hline \multirow{2}{*}{ Safety } & Decreasing air pollution \\
\hline
\end{tabular}




\section{Definition of Evaluation Criteria}

Traffic: This criterion includes the sub-criteria for increasing the using of public transport, reducing the traffic of single-seat vehicles and reducing driving violations.

Social Welfare: This criterion includes the sub criteria of reducing travel time and reducing travel costs. Zhang and Yang's studies were conducted in 2002 with the focus of large and single-minded cities, and the goal was to apply pricing policies to reduce congestion in the city center. Implementing the results of these studies in Shanghai, China showed that the time spent on different trips reduced the demand side and increased social welfare. The highest improvement was reported for journeys between 10 and 35 minutes [18].

Environmental: This criterion includes a sub- criterion for reducing air pollution. Based on the results of the research, Pak Gohar and Hooshangi far on the even and odd traffic plan in Tehran in 2006, on the even and odd traffic plan, although enjoying popularity and can add to the use of public cars, but cannot reduce the air pollution in the city of Tehran But it only affects the displacement of pollution and the distribution of air pollution in Tehran. Bandeira et al. (2012), using information gathered on the pricing of a freeway, examined the status of redirection of users in contrast to pricing in 2012, and the results showed that pricing could be significantly reduced in price NOx and CO pollutants are effective [17].

Safety: This criterion includes sub-criteria for reducing vehicle crashes by together and reducing vehicle crashes by motorcycles, bicycles and pedestrians.

\section{Determine the Weight of Criteria and Sub Criteria of Evaluation}

The AHP hierarchical model for evaluating the options studied in this paper is weighted to control traffic congestion in metropolitan areas at two levels. At the first level, the weight of each criterion and in the second level, the weight of the sub criteria for each criterion was calculated using the results of a questionnaire provided by 20 transportation experts and selected using "Expert Choice" software and paired comparisons are also compatible. The weight of each criterion and its sub-criteria are shown in Table 2.

Table 2. Weighting metrics for metropolitan traffic congestion control methods

\begin{tabular}{|c|c|c|c|c|}
\hline criteria & Sub criteria & $\begin{array}{c}\text { Weight of } \\
\text { criteria }\end{array}$ & $\begin{array}{c}\text { Weight of } \\
\text { sub criteria }\end{array}$ & $\begin{array}{c}\text { final weight of } \\
\text { sub criteria }\end{array}$ \\
\hline \multirow{3}{*}{ Traffic } & Increasing the using of public transport & \multirow{3}{*}{0.545} & 0.593 & 0.323 \\
\hline & Reducing the traffic of single-seat vehicles & & 0.304 & 0.166 \\
\hline & Reducing the driving violations & & 0.103 & 0.056 \\
\hline \multirow{2}{*}{$\begin{array}{c}\text { Social } \\
\text { Welfare }\end{array}$} & Decrease travel time & \multirow{2}{*}{0.216} & 0.710 & 0.153 \\
\hline & Reduce travel costs & & 0.290 & 0.063 \\
\hline Environmental & Decreasing air pollution & 0.124 & 1 & 0.124 \\
\hline \multirow{2}{*}{ Safety } & Reduce car crashes by car & \multirow{2}{*}{0.115} & 0.208 & 0.024 \\
\hline & Reducing vehicle crashes by motorcycles, bicycles and pedestrians & & 0.792 & 0.091 \\
\hline
\end{tabular}

\section{Scoring Options}

Scoring three available options to control traffic congestion in metropolitan areas have been done by using the average scores of 20 transport experts for each option in each of the sub-criteria considering the social and traffic conditions of the Mashhad metropolitan area. Whose results are shown in Table 3. The range of scoring for each option and in each sub- criterion is numerically between 0 and 100. It should be noted that in the pricing option, the option of pricing congestion in terms of the amount that is considered for the price of entering the traffic area limits, earns a different score in each sub-criterion. So that pricing is done at an optimum price.

Table 3. Scoring for metropolitan traffic congestion control options

\begin{tabular}{|c|c|c|c|c|c|}
\hline criteria & Sub criteria & $\begin{array}{c}\text { final weight of } \\
\text { sub criteria }\end{array}$ & $\begin{array}{l}\text { prohibited } \\
\text { traffic area }\end{array}$ & $\begin{array}{l}\text { alternate } \\
\text { traffic plan }\end{array}$ & $\begin{array}{c}\text { congestion } \\
\text { pricing }\end{array}$ \\
\hline \multirow{3}{*}{ Traffic } & Increasing the using of public transport & 0.323 & 59.1 & 54.2 & 74.2 \\
\hline & Reducing the traffic of single-seat vehicles & 0.166 & 20.6 & 38.4 & 38.6 \\
\hline & Reducing the driving violations & 0.056 & 22.5 & 40.1 & 51.4 \\
\hline \multirow{2}{*}{ Social Welfare } & Decrease travel time & 0.153 & 59.2 & 45.3 & 49.6 \\
\hline & Reduce travel costs & 0.063 & 39.4 & 28.5 & 65.2 \\
\hline Environmental & Decreasing air pollution & 0.124 & 27.5 & 54.6 & 39.7 \\
\hline \multirow[b]{2}{*}{ Safety } & Reduce car crashes by car & 0.024 & 43.7 & 69.4 & 57.1 \\
\hline & $\begin{array}{l}\text { Reducing vehicle crashes by motorcycles, } \\
\text { bicycles and pedestrians }\end{array}$ & 0.091 & 36.2 & 67.5 & 49.3 \\
\hline
\end{tabular}




\section{Ranking Options}

By multiplying each of the options for each sub-criterion in its weight, the weighted score of each option is determined for each sub-criterion. By adding the weighted scores of each of the options for sub-criteria, the final score of that option is obtained and the ranking of options is based on this final score. The ranking of options with the final score of each option is shown in Table 4.

Table 4. Final score and ranking of metropolitan traffic congestion control options

\begin{tabular}{ccccc}
\hline \multirow{2}{*}{ criteria } & Sub criteria & $\begin{array}{c}\text { prohibited } \\
\text { traffic area }\end{array}$ & $\begin{array}{c}\text { alternate } \\
\text { traffic plan }\end{array}$ & $\begin{array}{c}\text { congestion } \\
\text { pricing }\end{array}$ \\
\hline \multirow{2}{*}{ Traffic } & Increasing the using of public transport & 19.09 & 17.51 & 23.97 \\
& Reducing the traffic of single-seat vehicles & 3.42 & 6.37 & 6.41 \\
\hline \multirow{2}{*}{$\begin{array}{c}\text { Social } \\
\text { Welfare }\end{array}$} & Reducing the driving violations & 1.26 & 2.25 & 2.88 \\
\hline Environmental & Decrease travel time & 9.06 & 6.93 & 7.59 \\
\hline \multirow{2}{*}{ Safety } & Reduce travel costs & 2.48 & 1.8 & 4.11 \\
\hline & Decreasing air pollution & 3.41 & 6.77 & 4.92 \\
\hline & Reduce car crashes by car & 1.05 & 1.67 & 1.37 \\
\hline & bicycles and pedestrians & 3.29 & 6.14 & 4.49 \\
\hline
\end{tabular}

As shown in Table 4, the most suitable options for controlling traffic congestion in metropolitan areas based on their final score are congestion pricing, alternate traffic plan, and prohibited traffic area. According to the results of Table 4, in the traffic and social welfare criteria, the highest score earned by the traffic pricing and in the environmental and safety criteria, the highest score earned by the alternate route design (even and odd). For a better comparison of metropolitan traffic congestion control options, weighted scores for each option for each sub- criteria are graphically plotted in Figure 3.

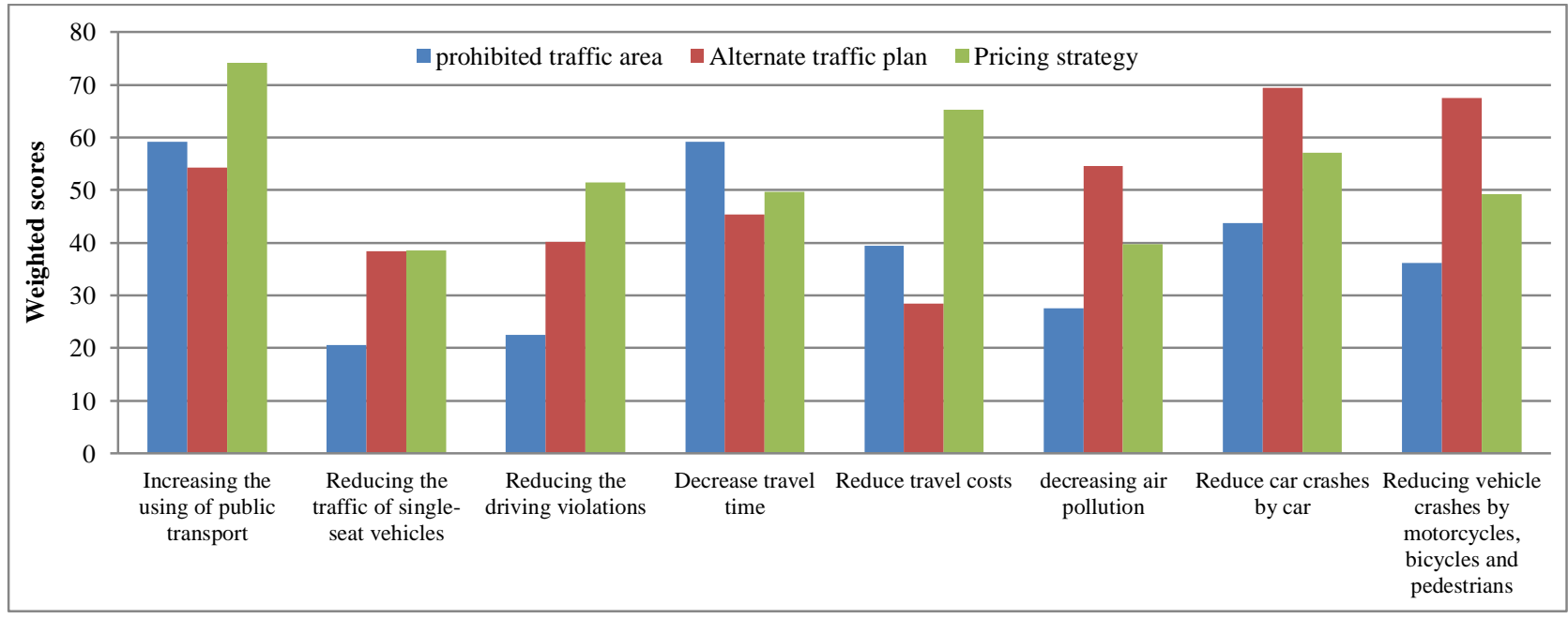

Figure 3. Weighted scores for each option of controlling metropolitan traffic congestion in each sub-criterion

\section{Conclusion}

- The most appropriate methods of traffic control in metropolitan cities are congestion pricing, alternate traffic plan (even and odd), and prohibited traffic area.

- In assessing the methods of controlling traffic congestion in metropolitan cities, the most important criteria for improving traffic conditions are improving social welfare, reducing environmental pollution and improving the safety of intra-city trips.

- Due to the Improving the traffic situation and increasing the use of public transport, reducing the traffic of singleengine vehicles and reducing driving violations, congestion pricing is preferred over the alternate traffic plan (even and odd) and prohibited traffic area. 
- In terms of increasing social welfare and indicators of reducing travel time and reducing travel costs, congestion pricing and prohibited traffic area have the same effect, and both are preferred over the alternate traffic plan (even and odd).

- In terms of reducing environmental pollution in the metropolitan cities, alternate traffic plan (even and odd) is preferred over the prohibited traffic area and congestion pricing.

- In terms of improving the safety of intra-city trips and reducing accidents, alternate traffic plan (even and odd) is preferred over the prohibited traffic area and congestion pricing.

\section{References}

[1] Carey, M., and Srinvasan, A., "Externalities, average and marginal costs, and Tolls on congested networks with time varying flows", Operational Research 41(February 1993): 217-231. Doi: 10.1287/opre.41.1.217.

[2] Yang, H. and .J. Huang, "carpooling and congestion pricing in a multilane highway with high-occupancy-vehicle lanes", Transportation research part A: Policy and practice, 33(February 1999): 139-155. Doi: 10.1016/S0965-8564(98)00035-4.

[3] Smith, M., "The marginal cost taxation of a transportation network", Transportation Research part B: Methodological 13(September 1979): 237-242. Doi: 10.1016/0191-2615(79)90015-8.

[4] Ahmadi Azari, K., Arintono, S., Hamid, H. and Davoodi, S.R., "Evaluation of demand for different trip purposes under various congestion pricing scenarios", Journal of Transport Geography 29(May 2013):43-51. Doi: 10.1016/j.jtrangeo.2013.01.001.

[5] Zhou, B., Bliemer, M.,Yang, H. and He, J., "A trial-and-error congestion pricing scheme for networks with elastic demand and link capacity constraints", Transportation Research part B: Methodological 72(February 2015): 77-92. Doi: 10.1016/j.trb.2014.11.009.

[6] De Lara, M., De Palma, A.,Kilani, M. and Piperno, S., "Congestion pricing and long term urban form- Application to Paris region”, Regional Science and Urban Economics 43(March 2013): 282-295. Doi: 10.1016/j.regsciurbeco.2012.07.007.

[7] Wang, Y., Liu, H., Friesz, T.L. and Yao, T., "Day-to-day congestion pricing and network resilience", Transportmetrica A: Transport Science 11(2015): 873-895. Doi: 10.1080/23249935.2015.1087234.

[8] Daganzo, C.F. and Lehe, L.J., "Distance-dependent congestion pricing for downtown zones", Transportation Research part B: Methodological 75(May 2015): 89-99. Doi: 10.1016/trb.2015.02.010.

[9] Amirgholy, M., Rezaeestakhruie, H. and Poorzahedy, H., "Multi-objective cordon price design to control long run adverse traffic effects in large urban areas", NETNOMICS: Economic Research and Electronic Networking 16(August 2015): 1-52. Doi: 10.1007/s11066-015-90-99-9.

[10] De Palma, A. and Lindsey, R., "Traffic congestion pricing methodologies and technologies”, Transportation Research part C: Emerging Technologies 19(December 2011):1377-1399. Doi: 10.1016/j.tcr.2011.02.010.

[11] Wang, C., Ghuddus, M. and Ison, S., "A spatio-temporal analysis of the impact of congestion on traffic safety on major roads in the UK”, Transportation Research part A: Transport Science 9(March 2011): 124-148. Doi: 10.1080/18128602.2010.538871.

[12] Cao, Z., Jiang, S., Zhang, J., and Guo, H., “A Unified Framework for Vehicle Rerouting and Traffic Light Control to Reduce Traffic Congestion", IEEE Transaction on Intelligent Transportation Systems 18(July 2017): 1958-1973. Doi: 10.1109/TITS.2016.2613997.

[13] Wang, Y., Cao, J., Li, W., and Shi, W., "Exploring traffic congestion correlation from multiple data sources", Pervasive and Mobile Computing 41(October 2017): 470-483. Doi: 10.1016/j.pmcj.2017.03.015.

[14] Wang, S., Dijahel, S., Zhang, Z., and McManis, J., "Next Road Rerouting- A Multiagent System for Mitigating Unexpected Urban Traffic Congestion", IEEE Transaction on Intelligent Transportation Systems 17(October 2016): 2888-2899. Doi: 10.1109/TITS.2016.2531425.

[15] Sun, H., Wu, J., Ma, Dan., and Long, J., "Spatial distribution complexities of traffic congestion and bottlenecks in different network topologies”, Applied Mathematical Modelling 38(January 2014): 496-505. Doi: 10.1016/j.apm.2013.06.027.

[16] Ding, H., Guo, F., Zheng, X., and Zhang, W., "Traffic guidance-perimeter control coupled method for the congestion in a macro network", Transportation Research Part C: Emerging Technologies 81(August 2017): 300-316. Doi: 10.1016/j.trc.2017.06.010.

[17] Bandeira, J., Coelho, M., Pimental, M., Khattak, A.,"Impact of intercity tolls in Portugal- An environmental perspective”, Procedia-Social and Behavioral Sciences 48(July 2012): 1174-1183. Doi: 10.1016./j.sbspro.2012.06.1093.

[18] Zhang, X., and Yang, H., "The optimal cordon-based network congestion pricing problem”, Transportation Research Part B: Methodological 38(July 2004): 517-537. Doi: 10.1016/j.trb.2003.08.001. 